\title{
"Unexplained" Dyspnoea and Shrinking Lungs in Systemic Lupus Erythematosus
}

\author{
B. I. HOFFBRAND, $* \ddagger$ M.A., B.M., M.R.C.P. ; E. R. BECK, $†$ M.B., B.SC., M.R.C.P.
}

Brit. med. F., 1965, 1, 1273-1277

Although the respiratory system is directly involved in a large proportion of cases of systemic lupus erythematosus (S.L.E.), little is known of the basic underlying pathological changes (Harvey, Shulman, Tumulty, Conley, and Schoenrich, 1954 ; Larson, 1961). Pleurisy and pleural effusions, which are usually bilateral and small, are well recognized (Winslow, Ploss, and Loitman, 1958). The pulmonary lesions of S.L.E. have been decribed radiologically as patchy pneumonitis, linear atelectasis, and diffuse and micronodular infiltration (Israel, 1953 ; Gould and Daves, 1958 ; Myhre, 1959 ; Alarcon-Segovia and Alarcon 1961). These terms presuppose a pathological basis for which there is remarkably little evidence in post-mortem findings (Purnell, Baggenstoss, and Olsen, 1955 ; Larson, 1961). Several writers have also commented on the occurrence of raised diaphragms, not accounted for by associated pulmonary or pleural involvement, which move slowly over a reduced range ("sluggishly") (Ellman and Cudkowicz, 1954 ; Harvey et al:, 1954 ; Myhre, 1959).

A patient with S.L.E. was seen in whom breathlessness, unexplained by physical and radiological examination, had been a major symptom for many years. Lung-function studies performed early in her illness showed that she had small stiff lungs.

It was surprising to find how little attention has been paid in published work on S.L.E. to clinical manifestations of disordered lung function. We have, moreover, been unable to find any reference to a systematic evaluation by lung-function tests of pulmonary physiology in this disease. It was therefore decided to investigate the problem further. The resulting study has shown that "unexplained" dyspnoea is in fact a frequent finding in S.L.E. It is associated with a restrictive ventilatory defect (Comroe, Forster, Dubois, Briscoe, and Carlsen, 1962) which in its most severe form gives rise to shrinking lungs.

\section{Methods}

Selection of Cases.-We examined the notes of all patients in whom a diagnosis of S.L.E. was made at University College Hospital in 1955-63. In 24 cases the diagnostic criteria of the Medical Research Council (1961) Collagen Diseases and Hypersensitivity Panel were fulfilled.

Lung-function Tests.-Ten of the 24 cases were personally seen. All had postero-anterior full inspiratory chest $x$-ray films. Screening was performed where raised diaphragms or breathlessness were present. Forced vital capacity (F.V.C.) and forced expiratory volume in one second (F.E.V. $)$ were measured on a low-resistance spirometer (Bernstein, D'Silva, and Mendel, 1952). Peak expiratory flow rate (P.E.F.R.) was measured with a Wright peak flow meter (Wright and McKerrow, 1959). Diffusion of the lung for carbon monoxide (DLCO) was measured by a steady-state method (MacNamara, Prime, and Sinclair, 1959) which also gave the resting minute-ventilation and respiratory rate. Mixed venous $\mathrm{PCO}_{2}$ was measured by Campbell and Howell's (1960) rebreathing method. Lung compliance was estimated, using an intra-oesophageal balloon, pneumotachograph, and a closed-circuit spirometer system. An estimate of ventilation-perfusion imbalance was obtained from a simul-

* Medical Registrar, University College Hospital, London. + Senior Medical Registrar, University College Hospital, London. $\neq$ Present address : Whittington Hospital, London. taneous recording of the expired volume and expired carbon dioxide curve (Hoffbrand, in preparation).

One patient (Case 1) had been fully investigated some years before. She and several other patients had had noted in their hospital records vital capacity measurements, performed when dyspnoea was a prominent symptom and a source of concern to patient and physician alike.

Pathology.-All the available post-mortem reports were reviewed. The histological preparations of pulmonary tissue were re-examined, the old paraffin blocks being freshly sectioned and stained where necessary. The macroscopic and microscopical post-mortem respiratory system appearances are well documented in six of the nine patients who died.

\section{Clinical Results}

Of the 24 patients, 16 had involvement of the respiratory system attributable to S.L.E., 4 had coincident chest disease (2 pulmonary tuberculosis, 1 bronchiectasis, 1 pneumonia due to septicaemia), and only 4 had normal chests. The current clinical state of those who underwent lung-function tests is shown in Table I.

The 16 patients with respiratory-system involvement showed, at varying times in their illness, one or more of the following three clinical patterns: (1) Pleurisy, usually bilateral and without a large effusion, often associated with pericarditis, fever, and

TABLE I.-Clinical Data at the Time of Lung-function Study in 10 Cases

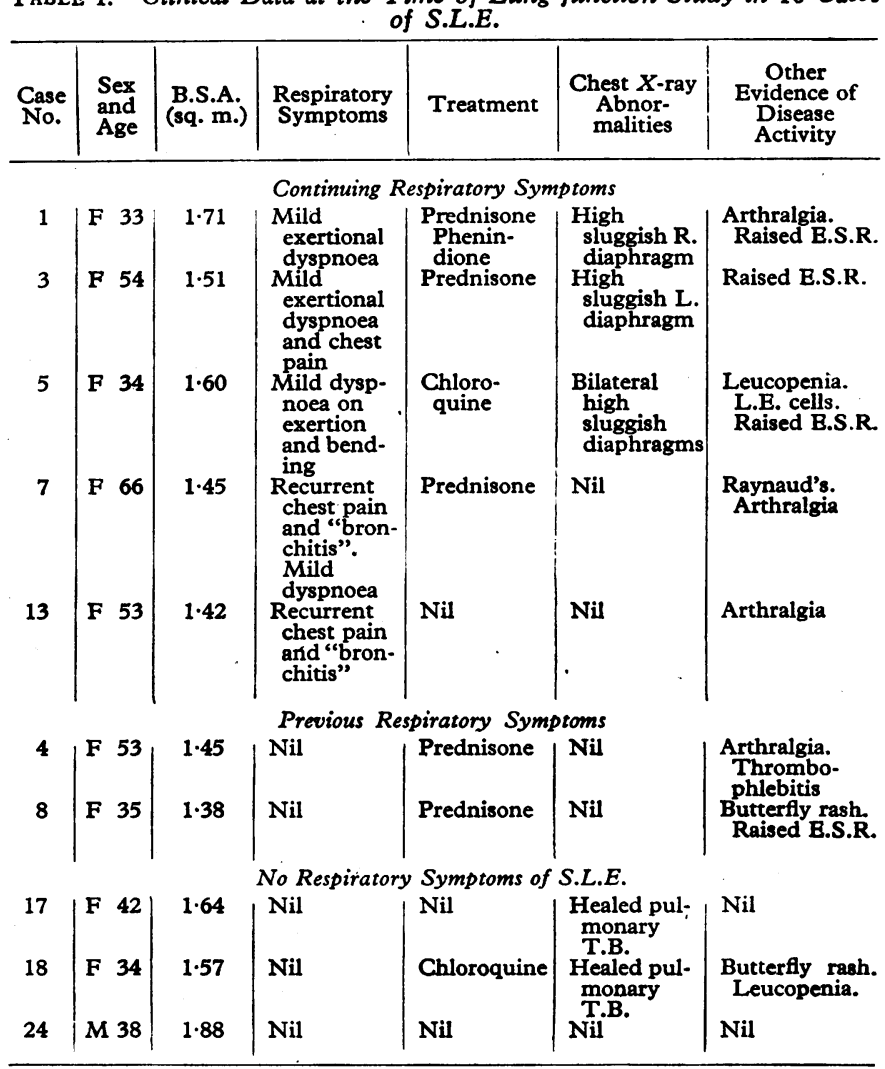


toxaemia. (2) Recurrent febrile attacks of cough, dyspnoea, pleurisy, and scanty sputum, resembling bronchopneumonia or bronchitis but not responding to antibiotics, and improving dramatically with steroid therapy. (3) Unexplained breathlessness following and often punctuated by the clinical patterns described in 1 and 2 ; such patients (Cases 1 to 8 ) were breathless when all clinical and radiological signs had resolved with the significant exception of raised sluggish diaphragms.

In all cases heart failure, hypertension, anaemia, and uraemia were absent and could not have been responsible for the dyspnoea.

This third clinical pattern does not appear to have been clearly described elsewhere. Two representative case histories are given below, with details of all other breathless patients. Of this third group of eight patients all except two who died (Cases 2 and 6$)$ were personally seen and studied.

\section{Case 1}

In February 1953 a 23-year-old typist developed right-sided abdominal pain with fever and tachycardia, and underwent laparotomy for suspected appendicitis, nothing abnormal being found. Her fever and tachycardia persisted, and on the eighth post-operative day she developed sudden right pleuritic pain with breathlessness and haemoptysis, diagnosed as pulmonary infarction. She was treated with anticoagulants. During the next 18 months she had recurrent venous thromboses in each leg.

During 1954 she began to have episodes of right chest pain and dry cough, worse on deep breathing or lying on the left, associated with breathlessness on climbing stairs or lying flat. Investigations revealed marked limitation of chest expansion, and chest $x$-ray examination showed a right pleural reaction and elevation of the right diaphragm. She was generally unwell, with a raised temperature and joint and muscle pains. In January 1955 these symptoms increased and pain developed in both sides of the chest. She was breathless after one flight of stairs and complained of being unable to take a deep breath. Examination showed facial erythema (" butterfly rash"); respirations were rapid and shallow, and were unaltered by effective analgesics given for her chest pain. The diagnosis of S.L.E. was confirmed by the finding of L.E. cells in the blood. Chest $x$-ray film showed small bilateral pleural effusions and elevation of the right diaphragm, which moved sluggishly on screening. Her vital capacity was greatly reduced, to $650 \mathrm{ml}$. Further studies showed that she had extremely small rigid lungs (details below). Because of these findings she was given steroids. There was an immediate improvement of her breathlessness with an increase in the vital capacity to $975 \mathrm{ml}$.

Her disease has been precariously suppressed since then by steroids and anticoagulants. When her maintenance steroid dose was reduced she noticed a return of breathlessness and arthralgia. Her vital capacity continued to improve on treatment to $1,630 \mathrm{ml}$. in 1956 , and $2,100 \mathrm{ml}$. in 1963. She has never shown clinical, radiological, or E.C.G. evidence of pulmonary hypertension.

\section{Case 2}

In June 1951 a 39-year-old housewife developed a constant dull ache in her left chest, worse on deep breathing. A small left pleural effusion was confirmed by aspiration. In January 1952 she developed arthralgia of the hands and knees. Three weeks later she had an unproductive cough, with marked breathlessness on moving in bed or lying flat. She was febrile $\left(103-104^{\circ}\right.$ F. ; 39.4$40^{\circ}$ C.), weak, and had lost weight. She was admitted to hospital in February 1952 seriously ill. She was breathless lying in bed propped up with four pillows and had a tachypnoea of 35 a minute. She was not cyanosed or using the accessory respiratory muscles, but her chest expansion was greatly reduced, to less than $\frac{3}{4}$ in. $(1.9 \mathrm{~cm}$.). The percussion note and breath sounds were reduced at both bases; a pericardial friction rub was heard once. Chest $x$-ray examination showed small bilateral effusions, patchy intrapulmonary opacities in both lower zones, and bilateral elevation of the diaphragms. Various antibiotics and oxygen therapy made no impression on her worsening state. When steroids were started after L.E. cells were found in the blood she showed a marked improvement within a few days. Breathlessness and fever rapidly returned whenever attempts were made to reduce steroid dosage. She was readmitted for assessment in September 1952, when she was unable to climb a flight of stairs because of breathlessness.

In 1954 she developed weakness and wasting of both distal and proximal muscles of the limbs but not involving the trunk or chest. This was thought to be part of the primary disease process (a form of polymyositis ?). The vital capacity was first measured in March 1955 and was $810 \mathrm{ml}$; in April 1955 it was $915 \mathrm{ml}$. (predicted value 3,075 ml.). Screening in June 1956 showed sluggish bilateral raised diaphragms.

On her final admission in October 1958 she had developed dysphagia. Breathlessness now limited her to climbing four stairs. Review of her chest $x$-ray films showed increasing diaphragmatic elevation throughout her illness (Figs. 1-3). There was no clinical, radiological, or E.C.G. evidence of pulmonary hypertension. In January 1959 she collapsed and died owing to perforation of an oesophageal ulcer (see below for pathological findings).

\section{Other Cases}

Cases 3 and 4 presented similarly with acute bilateral pleurisy, fever, arthralgia, and dyspnoea. The last-mentioned symptom persisted after the other initial symptoms had improved with steroid therapy. Case 3 had raised sluggish diaphragms, which have remained unchanged since. This patient has a greatly reduced exercise tolerance and complains of tiredness and inability to take a deep breath, but her psychoneurosis makes evaluation of these symptoms difficult. Vital capacity in Case 4 was $1,340 \mathrm{ml}$. (predicted

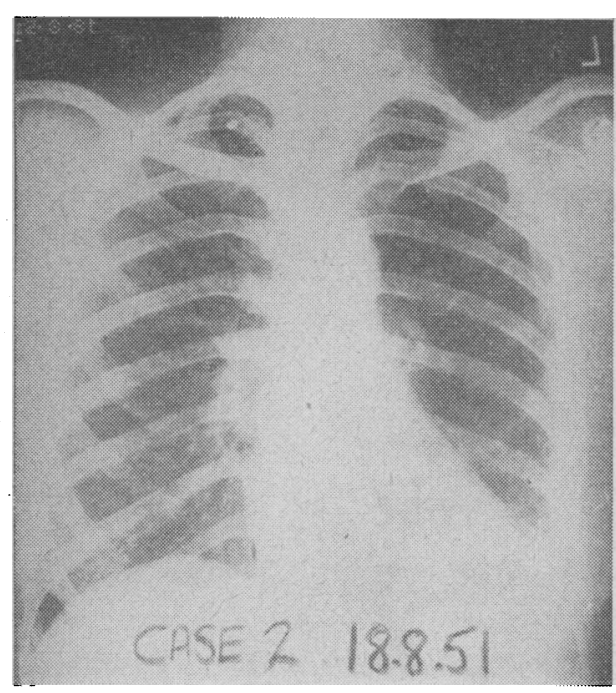

FIG. 1

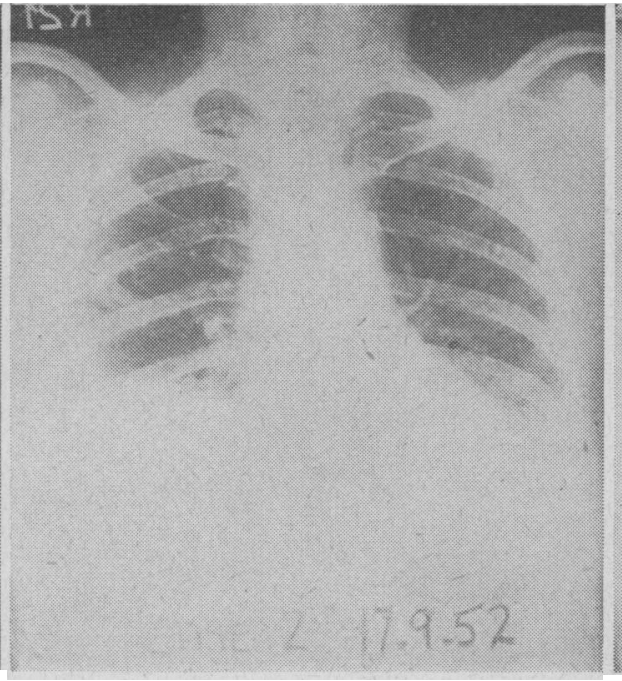

FIG. 2.

FIGs. 1-3.-Case 2. Radiographs showing progressive elevation of diaphragms.

FIG. 3 
$2,790 \mathrm{ml}$.). At the time of writing she had no chest symptoms and was well enough to walk 9 miles $(14.5 \mathrm{~km}$.) in the Lake District.

Case 5, like Case 1, became acutely ill with fever, pericarditis, bilateral pleurisy, and dyspnoea after exploratory laparotomy for abdominal pain. Chest $x$-ray films showed raised sluggish diaphragms. Her dyspnoea persisted after her other initial symptoms had disappeared on steroid therapy. In the absence of physical signs she was considered hysterical, until her vital capacity was found to be grossly reduced at $900 \mathrm{ml}$. (predicted 3,300 ml.). Although her radiological signs and vital capacity have changed little, she now has only slight reduction of her exercise tolerance, though complaining of breathlessness on bending down.

Case 6 was incapacitated by progressive dyspnoea over seven years, successively giving up riding a bicycle and his work as a greengrocer. Eventually he was limited to climbing a few stairs. Steroid therapy gave dramatic relief and dyspnoea was not again a prominent symptom up to his death. Prior to steroid therapy he had recurrent "pneumonic" episodes, in one of which a rounded shadow was seen to change over a few weeks into a linear opacity (Figs. 4 and 5). Apart from these acute episodes, his chest $x$-ray films were normal in spite of his crippling dyspnoea.

Case 7 has had recurrent attacks of cough, dyspnoea, fever, and pleurisy, affecting both sides of the chest, with mucoid sputum, leucopenia, and $x$-ray evidence of patchy pulmonary opacities. There was no response to antibiotics. Between these attacks she has been dyspnoeic on exertion, and complains of inability to take a deep breath. Since starting steroids two years ago the acute episodes have become fewer and less severe and her chronic dyspnoea has improved.

Case 8 had dyspnoea for two years (following an attack of pleurisy), limiting her to climbing eight stairs. The symptom improved on steroid therapy.

Dyspnoea was also prominent in three patients (Cases 9, 10, and 11) who died before this study and in whom the symptom is difficult to evaluate. Case 9 had recurrent acute episodes of fever, cough, sputum, pleurisy, and dyspnoea. She was dyspnoeic between attacks, with deterioration in her exercise tolerance after every attack. When first seen at this hospital she was, however, hypertensive and uraemic. Case 10 was dyspnoeic because of large bilateral pleural effusions which developed after thoracotomy for sympathectomy for Raynaud's phenomena. The dyspnoea of Case 11 could have been related to uraemia, hypertension, and the nephrotic syndrome.

\section{Lung-function Tests}

The results of our lung-function study are given in Table II. Apart from ventilation-perfusion imbalance in Case 18, with extensive healed pulmonary tuberculosis, the only abnormalities were found in those patients with persisting chest symptoms. These indicate a restrictive defect of ventilation with the occurrence of tachypnoea, reduced vital capacity, reduced lung compliance, and minor degrees of ventilation-perfusion imbalance. There was no airways obstruction, the F.E.V. ${ }_{1}$ /F.V.C. ratio being over $65 \%$ and the P.E.F.R. within the normal range (Flint and Kahn, 1962). The resting DLco was within the normal limits for this laboratory, though in the lower range. In the four cases in which it was measured (Cases 1, 13, 18, and 24) the DLCO showed a normal increase on exercise. The vital capacity expressed as a percentage of the predicted normal for the four currently breathless cases (Nos. 1, 3, 5, and 7) is significantly less $(\mathrm{P}<0.01)$ than that of those who were not breathless at the time of study.

Table III shows the results of investigations carried out at the Brompton Hospital in Case 1 when
TABLE II.-Lung-function Studies in 10 Cases of S.L.E.

\begin{tabular}{|c|c|c|c|c|c|c|c|c|c|c|}
\hline \multirow[b]{2}{*}{ 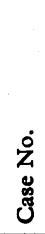 } & \multicolumn{2}{|c|}{ F.V.C. } & \multirow{2}{*}{ 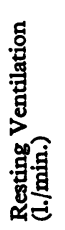 } & \multirow{2}{*}{ 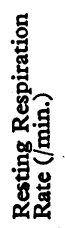 } & \multirow[b]{2}{*}{ 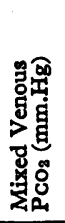 } & \multirow[b]{2}{*}{ 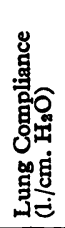 } & \multirow[b]{2}{*}{ 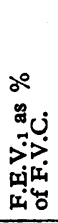 } & \multirow[b]{2}{*}{ 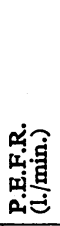 } & \multirow{2}{*}{ 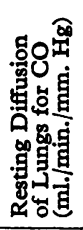 } & \multirow[b]{2}{*}{ 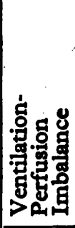 } \\
\hline & శ్며 & 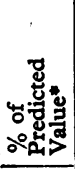 & & & & & & & & \\
\hline $\begin{array}{r}1 \\
3 \\
5 \\
7 \\
13 \\
13 \\
4 \\
8 \\
17 \\
18 \\
24\end{array}$ & $\begin{array}{l}2,100 \\
1,750 \\
1,300 \\
1,750 \\
2,600 \\
2,550 \\
2,800 \\
3,200 \\
3,250 \\
5,800\end{array}$ & $\begin{array}{r}75 \\
77 \\
44 \\
77 \\
105 \\
99 \\
108 \\
110 \\
112 \\
127\end{array}$ & $\begin{array}{r}10.4 \\
7.1 \\
7.9 \\
7.4 \\
7.3 \\
7.5 \\
8.9 \\
5.3 \\
7.7 \\
11.0\end{array}$ & $\begin{array}{l}26 \\
20 \\
11 \\
13 \\
19 \\
12 \\
19 \\
10 \\
17 \\
16\end{array}$ & $\begin{array}{l}48 \\
43 \\
45 \\
47 \\
\\
44 \\
46 \\
42 \\
\end{array}$ & $\begin{array}{c}0.069 \\
0.046 \\
0.080 \\
= \\
= \\
= \\
=\end{array}$ & $\begin{array}{l}74 \\
77 \\
92 \\
69 \\
90 \\
76 \\
80 \\
90 \\
79 \\
83\end{array}$ & $\begin{array}{l}285 \\
244 \\
205 \\
246 \\
370 \\
362 \\
390 \\
380 \\
427 \\
650\end{array}$ & $\begin{array}{r}12.3 \\
8.5 \\
13.2 \\
9.8 \\
9.6 \\
9.0 \\
12.1 \\
9.3 \\
10.1 \\
16.1\end{array}$ & $\begin{array}{l}+ \\
x \\
x \\
+ \\
= \\
\\
x \\
x \\
+ \\
x\end{array}$ \\
\hline
\end{tabular}

* Needham, Rogan and McDonald (1954).
$+=$ Present.
$x=$ Absent. Not done.

TABLE III.-Lung-function Studies in Case 1

\begin{tabular}{|c|c|c|c|}
\hline & & February 1955 & $\begin{array}{c}\text { February } 1956 \\
\text { (on Steroids) }\end{array}$ \\
\hline 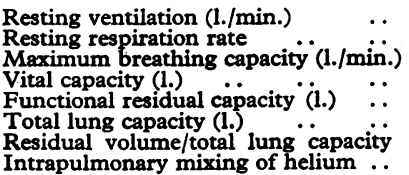 & $\begin{array}{l}\ldots \\
\cdots \\
\cdots \\
\cdots \\
\cdots\end{array}$ & $\begin{array}{c}7.5 \\
20-30 / \min \\
25 \cdot 5 \\
0.65 \\
1.50 \\
1.85 \\
0.65 \\
\text { Normal }\end{array}$ & $\begin{array}{c}\overline{7} \\
46 \\
1 \cdot 63 \\
1.60 \\
2 \cdot 65 \\
0.38 \\
\text { Normal }\end{array}$ \\
\hline
\end{tabular}

this patient was severely disabled by dyspnoea in 1955, and when she had considerably improved clinically after 12 months' steroid therapy. These investigations showed tachypnoea with a gross reduction of vital capacity, total lung capacity, and maximum breathing capacity. The intrapleural-pressure swing, measured with an intraoesophageal catheter, on quiet respiration was about ten times normal (Dr. F. J. Prime). The patient thus had a restrictive ventilatory defect with small stiff lungs. The tests showed a distinct improvement one year later, in keeping with the reduction in the severity of her dyspnoea.

The vital-capacity values measured in Cases 2,4 , and 5 when these patients were extremely breathless at rest are given in the clinical section above. They are all well below the predicted range and show a similar improvement on steroid therapy.

\section{Pathology}

The diagnosis of S.L.E. was confirmed in all six cases on the basis of the cardiac and renal findings. Two of these (Cases 2 and 6) had " unexplained" dyspnoea.

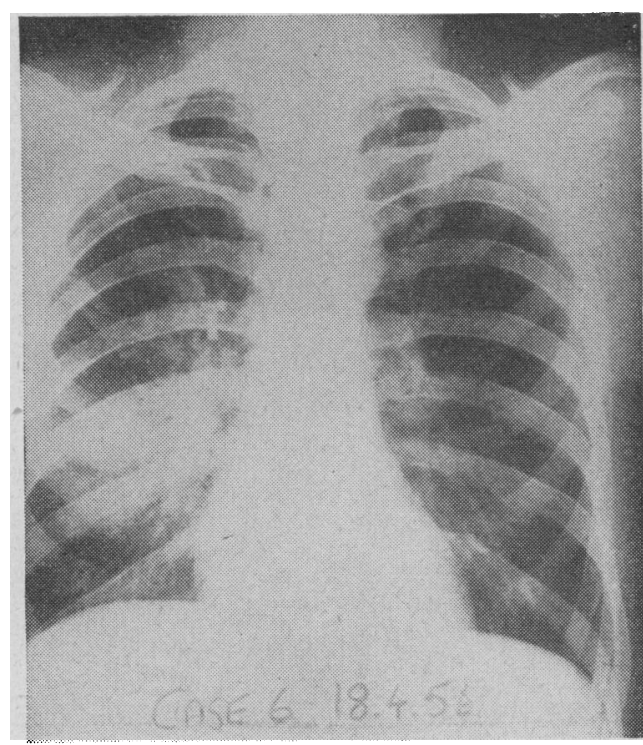

FIG. 4

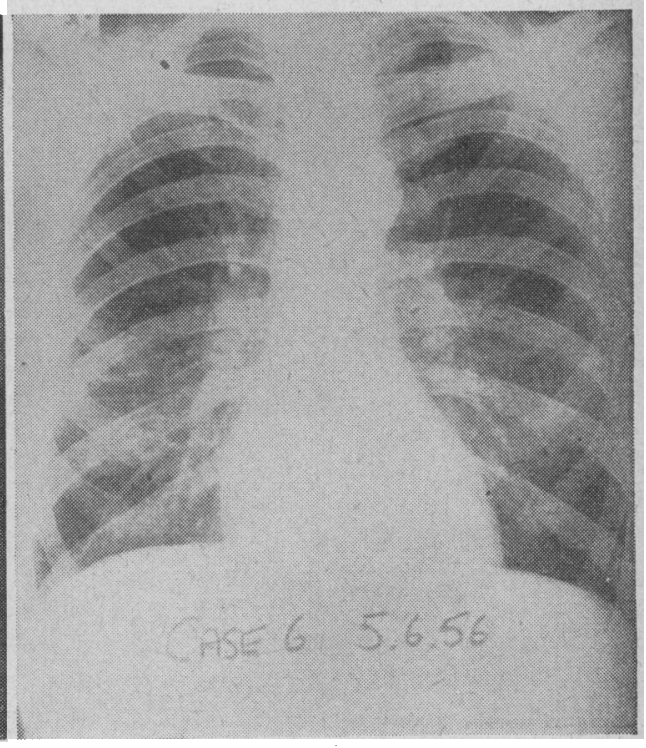

FIG. 5
FIGS. 4 and 5.-Case 6. Radiographs showing rounded opacity changing to linear shadow. 
Case 2 showed bilateral fibrous pleural adhesions over the greater part of both lungs. The only available sections show oedema of both lungs and bronchopneumonia with pinkstaining hyaline material lining some alveoli. The intrapulmonary arteries were normal and there was no right ventricular hypertrophy. The other patient (Case 6) died of miliary tuberculosis, which overshadowed other possible pulmonary findings. He had bilateral easily separated fibrous pleural adhesions. The intrapulmonary vasculature, however, was normal and there was no right ventricular hypertrophy.

Two patients (Cases 9 and 11), who were inadequately documented clinically but in whom breathlessness occurred, had respiratory-system changes. Case 9 showed extensive fibrous pleural adhesions and small lungs with some basal collapse. There was thickening of pulmonary blood-vessels with emboli in one area associated with a red infarct. There was slight generalized myocardial hypertrophy. Case 11 showed an acute arteritis with fibrinoid necrosis of many medium-sized pulmonary vessels.

One patient (Case 12) who died of severe toxaemia with a terminal bronchopneumonia had easily separated bilateral fibrous pleural adhesions and areas of consolidation containing large mononuclear cells.

Case 21 showed terminal pulmonary oedema only.

\section{Discussion}

The incidence and clinical varieties of previously recognized pleuropulmonary involvement in this series of cases of S.L.E. are similar to those of other authors. As others have noted, pleuropulmonary involvement may be the presenting feature of S.L.E. or may occur at any stage in its course. There was, however, little evidence that infections were' responsible for any but terminal changes (cf. Israel, 1953).

It is apparent from published case reports that breathlessness is a common symptom in S.L.E. The cause of such dyspnoea is usually unspecified and not ascertainable from the clinical details given. It is perhaps not surprising that the significance of a highly subjective symptom in generally ill and often mentally disturbed patients is minimized: However, a few workers have remarked on the occurrence of severe dyspnoea in S.L.E. Ellman and Cudkowicz (1954) report two cases in which the main disability was breathlessness, present in one case even at rest. These patients had low vital capacities with basal pleural thickening and sluggish raised diaphragms but no other apparent cause for their severe symptom. Whitfield (1959) thought the degree of dyspnoea in his 10 cases of S.L.E. with acute pleuropericarditis was much greater than expected from the physical and radiological signs in the chest. The chest $x$-ray films of his cases showed elevation and fixity of the diaphragms with basal pleural reactions. Only two cases had pulmonary lesions. Richardson (1963) also comments on dyspnoea. in S.L.E. occurring even at rest. He attributes the severity of this symptom to splinting of the lungs by pleural fibrosis.

Breathlessness for no obvious cause occurred in at least 8 of the 24 cases of S.L.E. in the present series-an incidence of $33 \%$. These patients had tachypnoea and a reduced chest expansion, but no cyanosis, clubbing, or abnormal auscultatory signs. At least three patients were orthopnoeic. There was no relationship of the dyspnoea to pleuritic chest pain, though several patients complained of a bilateral ache in their chest on deep inspiration. The usual $x$-ray findings in these cases were of raised diaphragms moving sluggishly, but never paradoxically, on screening. Although dyspnoea often improved considerably on steroid therapy, the vital capacity improved less dramatically, and the diaphragms, once raised and sluggish, never returned to normal. In those cases without diaphragmatic elevation, and presumably less severely affected, complete recovery from dyspnoea seems to have occurred. It seems likely that improve- ment in dyspnoea is at least partly due to adaptation by the patient to his disability. There was no evidence in any case of pulmonary hypertension.

The lung-function studies and the isolated extremely low vital-capacity results are highly suggestive of a restrictive defect of ventilation. Such a defect offers an explanation for the raised sluggish diaphragms characteristic of S.L.E., and which in our experience are always associated with dyspnoea. Thus the raised position probably results from the reduced total lung capacity. The diminished range of movement in the proved absence of increased airways resistance is due to reduced lung compliance. In other words, the poor range of movement indicates a small lung-volume change for the maximum transpulmonary-pressure changes involved in full inspiration and expiration.

It has been suggested that the abnormal diaphragmatic position and movements in S.L.E. are due to pleural fibrosis (Myhre, 1959 ; Richardson, 1963). Such fibrosis could theoretically account also for some of our clinical and physiological findings. However, the degree of pleural fibrosis found radiologically (and at necropsy in Cases 2 and 6) does not appear sufficient to play more than a minor part in the clinical picture. Moreover, we cannot explain the steroid-induced improvement in dyspnoea and lung function on this basis.

The abnormal diaphragmatic findings in S.L.E. are not perhaps as widely appreciated as they should be, and are not included by Gould and Daves (1958) in a recent review of the radiological features of this disease. The chest $x$-ray findings are thus liable to misinterpretation. Ellman and Cudkowicz (1954) and Myhre (1959) record patients with S.L.E. explored for subphrenic abscess on the basis of pyrexia and raised diaphragm with a pleural reaction.

Thrombo-embolic pulmonary hypertension must always be considered in the differential diagnosis of unexplained breathlessness, especially when chest pain and peripheral venous thrombosis are as prominent as in S.L.E. In fact, one patient (Case 1) almost certainly had pulmonary infarction at the onset of her illness. There was, however, no evidence of pulmonary hypertension in life or at necropsy in any of the dyspnoeic patients with S.L.E. reported here. Pulmonary hypertension secondary to an arteritis of the smaller pulmonary vessels has been described in S.L.E. (Aitchison and Williams, 1956). The differential diagnosis is complicated by the similarity of the lung-function changes in S.L.E. and in thrombo-embolic pulmonary hypertension (Goodwin, Harrison, and Wilcken, 1963) and by the fact that the chest $x$-ray changes in S.L.E. and acute pulmonary embolism are alike (Gould and Daves, 1955). The clinical and lung-function response to steroids seen in S.L.E. would not, however, be expected to occur in thrombo-embolic pulmonary hypertension.

The nature of the processes occurring in the lungs in S.L.E. is unknown. The problem of correlating necropsy findings with pulmonary changes observed during life was stressed by Klemperer, Pollack, and Baehr in 1941. The pathological changes due to S.L.E. itself are often obscured by infection, heart failure, and uraemia. Pulmonary fibrosis, which is a prominent feature of scleroderma (Hughes and Lee, 1963) and occurs in rheumatoid arthritis (Lee and Brain, 1962), is rare in S.L.E. (Purnell et al., 1955). We have been unable to find a single case reported of diffuse interstitial pulmonary fibrosis in S.L.E., although this association is said to occur (Ellman, 1958).

There is evidence in the literature that alveolar atelectasis is an important feature of the lung changes of S.L.E. and that it is associated with severe dyspnoea. Rakov and Taylor (1942) and Foldes (1946) each described a case of S.L.E. whose main complaint was breathlessness. Foldes's case, in particular, resembles ours in having had no clinical or radiological signs in the chest (the diaphragms are not commented on). In both cases necropsy revealed the extremely unusual finding of gross atelectasis in the absence of bronchial obstruction or external 
compression of the lungs. The main histological features were an interalveolar infiltration of predominantly mononuclear cells and loss of alveolar architecture with intra-alveolar hyaline material. The authors of both papers comment on the absence of fibrosis and pneumonia. Baggenstoss (1952) also has seen such cases showing the features of what Foldes has termed an atelectizing pneumonitis. The seven cases of pulmonary S.L.E. of Harvey et al. (1954) which came to necropsy showed changes "such as to give focal atelectasis." Hyaline-membrane formation was again prominent, and two at least of these patients died of respiratory failure. In addition, diffuse atelectasis was found in $15(28 \%)$ of the 54 necropsy cases of S.L.E. of Purnell et al. (1955).

Such pathological changes offer an explanation for the clinical and physiological picture of shrinking lungs in S.L.E. Significant alveolar atelectasis can occur in the absence of radiological changes in the lungs (Bendixen, 1963), while more focal atelectasis could give rise to the radiological features called patchy pneumonitis, infiltration, and linear atelectasis. Widespread alveolar atelectasis would also give the lung-function abnormalities, among which loss of lung volume is predominant (described above), and by alterations in the mechanical properties of the lungs would give dyspnoea. Moreover, such atelectasis, giving rise to an intrapulmonary shunt of unsaturated venous blood, could account for cyanosis not responding to $100 \%$ oxygen which has been noted in several cases of severe pulmonary S.L.E.-for example, Cases 21 and 22 of Harvey et al. (1954). It seems likely that the absence of gross atelectasis in our two breathless patients who came to necropsy, and in more recent necropsy studies in S.L.E., is due to steroid therapy, which is so effective clinically.

The possible pathogenesis of such atelectasis is not obvious. Foldes (1946) and Baggenstoss (1952) attributed it in their cases to inflammatory processes in the alveolar walls and perivascular and peribronchial connective tissues. An arteritis of the bronchial vessels has also been suggested as a possible cause of the pulmonary changes of S.L.E. (Ellman and Cudkowicz, 1954). The presence of hyaline membrane lining the alveoli was noted by Rakov and Taylor (1942), by Foldes (1946), and by Harvey et al. (1954). It also occurred in our Case 2, with shrinking lungs. Hyaline-membrane formation has been described in many conditions (Lancet, 1962), but it is especially prominent in the respiratory-distress syndrome of the newborn. In this condition the surface film lining the alveoli of the normal aerated lung is absent, and the resultant excessive surface tension results in atelectasis and hyaline-membrane formation (Pattle, Claireaux, Davies, and Cameron, 1962). The occurrence of atelectasis and hyaline-membrane formation in the lungs in S.L.E. suggests that deficiency of the surface film-a lipoprotein (Pattle and Thomas, 1961) and thus liable to become involved in immunological processes-may be responsible for the changes in the mechanical properties of the lungs in this condition.

\section{Summary}

A review of the respiratory-system changes in a series of 24 patients with S.L.E. has been made. This confirms previous reports of a high incidence of primary respiratory involvement in this condition.

Breathlessness for no obvious cause occurred in one-third of the cases studied. Clinical, radiological, and physiological findings suggest that this dyspnoea is associated with a change in the mechanical properties of the lungs, which become small and stiff. The vital capacity is particularly reduced, and simple spirometry may be useful in the diagnosis of pulmonary involvement in S.L.E. and in following the response to treatment.

It is suggested that the main pathological change is alveolar atelectasis. A tentative hypothesis to account for this is a deficiency of the surface-tension-reducing film that lines the alveoli of the normal aerated lung.

\section{Addendum}

Since this manuscript was prepared a further case of S.L.E. with "unexplained" breathlessness has been studied. The patient was a 29-year-old man who in addition to severe breathlessness, present at rest, had arthritis, Raynaud's phenomenon, parotid-gland and lymph-node enlargement, attacks of pleurisy, rash, and intermittent fever. Chest $x$-ray examination initially showed a pleural reaction and linear opacity at one base.

Shortly after admission to hospital the patient had an acute pneumonic illness with basal shadowing on his chest $x$-ray picture. There was no response to antibiotics but a dramatic improvement with steroids.

Lung-function tests, kindly performed by Dr. M. L. Thomson, were made for the first time when the patient was on steroids but still breathless at rest. His chest $x$-ray picture at this time showed slight linear opacities at the bases and restricted diaphragmatic movement on screening. The tests demonstrated a marked proportionate reduction in all components of the lung volume-vital capacity, functional residual capacity, total lung capacity, and residual volume being, respectively, 50.5, 47, 37, and $48 \%$ of predicted normal. Lung compliance was 0.125 $1 . / \mathrm{cm} . \mathrm{H}_{2} \mathrm{O}$, and there was no evidence of airways obstruction, a diffusion block, or ventilation-perfusion abnormalities. These results closely resemble those of Case 1 described above.

Since this paper was accepted for publication a report of a pulmonary function study in S.L.E. has appeared (Huang et al., 1965). The findings of these workers are on the whole in close agreement with our own.

We wish to thank the physicians of University College Hospital for access to their case records ; Dr. Peter Sutton for details of the pathology ; Dr. F. J. Prime for the lung-function results in Case 1 ; and Professor M. L. Rosenheim, Dr. Howard Nicholson, Dr. P. J. D. Heaf, and Dr. P. 'M. S. Gillam for help in the preparation of the manuscript.

\section{REFERENCES}

Aitchison, J. D., and Williams, A. W. (1956). Ann. rheum. Dis., 15, 26. Alarcon-Segovia, D., and Alarcon, D. G. (1961). Dis. Chest., 39, 7. Baggenstoss, A. H. (1952). Proc. Mayo Clin., 27, 412.

Bendixen, H. H. (1963). Quoted by H. H. Bendixen, J. Hedley-Whyte, and M. B. Laver, New Engl. F. Med., 1963, 269, 991 .

Bernstein, L., D'Silva, J. L., and Mendel, D. (1952). Thorax, 7, 255.

Campbell, E.. J. M., and Howell, J. B. L. (1960). Brit. med. F., 1, 458.

Comroe, J. H., Forster, R. E., Dubois, A. B., Briscoe, W 1,458 . Carlsen, E. (1962). The Lung, 2nd ed. Year Book Medical Publishers, Chicago.

Ellman, P.'(1958). Proc. roy. Soc. Med., 51, 654

and Cudkowicz, L. (1954). Thorax, 9, 46.

Flint, F. J., and Khan, M. O. (1962). Brit. med. \%., 2, 1231.

Foldes, J. (1946). Amer. f. clin. Path, 16, 160

Goodwin, J. F., Harrison, C. V., and Wilcken, D. E. L. (1963). Brit. med. 7. 1, 707, 777.

Gould, D. M., and Davies, M. L. (1955). F. chron. Dis., 2, 136.

Gould, D. (1958). Amer. F. med. Sci., 235, 596

Harvey, A. M., Shulman, L. E., Tumulty, P. A., Conley, C. L., and Schoenrich, E. H. (1954). Medicine (Baltimore), 33, 291.

Huang,C.-T., Hennigar, G. R., and Lyons, H. A. (1965). New Engl. \}. Med., $272,288$.

Hughes, D. T. D., and Lee, F. I. (1963). Thorax, 18, 16.

Israel, H. L. (1953). Amer. F. med. Sci., 226, 387. Klemperer, P., Pollack, A. D., and Baehr, G. (1941). Arch. Path., 32,

Lancet, 1962, 1, 362. Larson, D. L. (1961). Systemic Lupus Erythematosus. Churchill,

Lee, F. I., and Brain, A. T. (1962). Lancet, 2, 693.

MacNamara, J., Prime, F. J., and Sinclair, J. D. (1959). Thorax, 14, 166.

M.R.C. (1961). Brit. med. f., 2, 915

Myhre, J. R. (1959). Acta med. scand., 165, 55

Needham, C. D., Rogan, M. C., and McDonald, I. (1954). Thorax, 9, 313.

Pattle, R. E., Claireaux, A. E., Davies, P. A., and Cameron, A. H. (1962). Lancet, 2, 469.

and Thomas, L. C. (1961). Nature (Lond.), 189, 844

Purnell, D. C., Baggenstoss, A. H., and Olsen, A. M. (1955). Ann. intern. Med., 42, 619.

Rakov, H. L., and Taylor, J. S. (1942). Arch. intern. Med., 70, 88.

Richardson, J. (1963). Connective Tissue Disorders. Blackwell, Oxford. Whitield, J (1959).Brit o Dis Chest 53. B

Winslow, W. A., Ploss, L. N., and Loitman, B. (1958). Ann. intern Med. 49,70 .

Wright, B. M., and McKerrow, C. B. (1959), Brit. med. f., 2, 1041. 